\title{
Design, characterization and in vitro evaluation of HPMC K100 M CR loaded Fexofenadine $\mathrm{HCl}$ microspheres
}

\author{
Paroma Arefin *iD, Ikramul Hasan and Md. Selim Reza
}

\author{
${ }^{*}$ Correspondence: \\ paroma.arefin@gmail.com \\ Department Pharmaceutical \\ Technology, Faculty \\ of Pharmacy, University \\ of Dhaka, Dhaka 1000, \\ Bangladesh
}

\begin{abstract}
The aim of the current study was to formulate Fexofenadine hydrochloride loaded sustained release microspheres using HPMC K100 M CR, a release retardant hydrophilic polymer by solvent evaporation method. The effect of different drug loading on drug content, drug encapsulation efficiency and release of drug was monitored. The studies on in vitro release mechanism were performed using USP paddle method with $900 \mathrm{ml}$ of phosphate buffer ( $\mathrm{pH}$ 6.8) for $10 \mathrm{~h}$ at $100 \mathrm{rpm}$. The mechanism of the drug release was determined by fitting in vitro release data to various release kinetic models such as the zero order, first order, Higuchi, Hixson Crowell and Korsemeyer-Peppas model and finding $R^{2}$ values for the release profile corresponding to each model. The results confirm that the release rate of the drug from the microspheres is highly affected by the drug to polymer ratio. The study finds that Higuchi release kinetics, KorsmeyerPeppas release kinetics and Hixson-Crowell release kinetics were the major release mechanism. The release mechanism was found to be non-Fickian with increase of polymer content. Scanning electron microscopic technique was performed to obtain the morphological changes due to different drug loading. Differential scanning calorimetry and Fourier transform infra-red spectroscopy was performed to determine any interaction of drug with the polymer. A statistically significant variation in release rate was observed for variation in the amount of HPMC K100 M CR. In the present study, a series of sustained release formulations of Fexofenadine hydrochloride were developed with different drug loading so that these formulations could further be evaluated from the in vivo studies. The formulations were found to be stable and reproducible.
\end{abstract}

Keywords: Emulsification-solvent evaporation, Fexofenadine $\mathrm{HCl}$, Microsphere

\section{Background}

Microspheres, a potential drug delivery system in the segment of novel drug delivery, are defined as structure made up of continuous phase of one or more miscible polymers in which drug particles are dispersed at the molecular or macroscopic level. Generally the size of the microencapsulated products (micro-particles) is considered as larger than 1-1000 $\mu \mathrm{m}$ in diameter (Parida et al. 2008). Among the several different methods of microencapsulation the most common are solvent evaporation, coacervation, coalescence and phase separation, interfacial polymerization, spray drying and ionotropic gelation. Solvent-evaporation method engages emulsification of a solution of polymer 
and drug with an additional medium in which the drug and polymer cannot dissolve. The technique is comparatively uncomplicated and has been used for the formulation of microcapsules of a range of compounds using several polymers of different purpose (Bolourtchian et al. 2005).

Fexofenadine $\mathrm{HCl}$ (FFN) is a second-generation nonsedating histamine $\mathrm{H}_{1}$ receptor antagonist extensively used in seasonal allergic rhinitis. The usual dose for adults is $60 \mathrm{mg}$ two times a day or $180 \mathrm{mg}$ once a day. The half life of the drug is $14.4 \mathrm{~h}$ and the oral bioavailability is $30-41 \%$ (Product Information: Allegra reviewed 1/2000). The adverse effect was reported to be anaphylaxis and hypersensitivity reactions (Product Information: Allegra reviewed 10/2001). As it is under the class III of the biopharmaceutical classification system (BCS), polymers can be used to prolong its duration of action in body, thereby increasing the bioavailability. Thus to increase the bioavailability by sustaining the action and to reduce the frequency of administration, to lessen adverse effects and to improve patient compliance, a controlled release formulation of the drug is required. Some extended release matrix tablets of Fexofenadine $\mathrm{HCl}$ are available in the market, but microspheres offer more consistent drug distribution and reduced dose dumping compared to matrix tablets.

This research aimed to develop polymeric microspheres of Fexofenadine $\mathrm{HCl}$ using HPMC K100 M CR polymer to offer sustained release delivery of the drug to aid in long term therapy with high margin of safety. HPMC K100 M CR is a hydrophilic release retardant polymerand is extensively studied for encapsulating material to develop controlled release dosage forms. Several researchers have investigated the utilization of HPMC K 100 M CR as a polymer to microencapsulate a drug utilizing emulsion solvent evaporation technique (Uddin et al. 2013; Raut et al. 2013).

\section{Methods}

\section{Materials}

Fexofenadine $\mathrm{HCl}$ was received as a generous gift from Incepta Pharmaceuticals Ltd. HPMC K100 M CR (Evonik Industries, Germany), ethanol (MERCK, Germany), $n$-hexane (MERCK, Germany), Span 80 (sorbitanmonooleate) (MERCK, Germany), light liquid paraffin (MERCK, Germany), potassium dihydrogen phosphate (MERCK, Germany) and dipotassium hydrogen phosphate (MERCK, Germany) were used in this study from the indicated sources.

\section{Preparation of microspheres of Fexofenadine HCl with HPMC K100 M CR polymer by solvent evaporation technique}

The microspheres of Fexofenadine $\mathrm{HCl}$ were prepared based on the "emulsion-solvent evaporation technique" using HPMC K100 M CR. Ethanol was used as solvent. Span80 was used as lipophilic surfactant for Fexofenadine $\mathrm{HCl}$ water in oil (W/O) type of emulsions (Ayon et al. 2014; Raval et al. 2011; Jalil and Nixon 1989).

\section{Formulation design}

Total five batches (each of $900 \mathrm{mg}$ ) of microspheres, designated as F1-F5 were prepared with Fexofenadine $\mathrm{HCl}$ (Table 1) using HPMC K100 M CR. 
Table 1 Formulation protocol for the microspheres prepared by using HPMC K100 M CR with different drug loading

\begin{tabular}{llll}
\hline Formulation & Drug:polymer & Drug $(\mathbf{m g})$ & Methocel K 100 M CR (mg) \\
\hline F1 & $2: 1$ & 600 & 300 \\
F2 & $1.5: 1$ & 540 & 360 \\
F3 & $1: 1$ & 450 & 450 \\
F4 & $1: 1.5$ & 360 & 540 \\
F5 & $1: 2$ & 300 & 600 \\
\hline
\end{tabular}

In vitro characterization of Fexofenadine $\mathrm{HCl}$ microspheres

\section{Production yield}

The yield (\%) was determined by the following equation (El-Kamel et al. 2006):

$$
\text { Yield }(\%)=\frac{\text { Weight of microspheres in grams }}{\text { Weight of total amount of materials added }} \times 100
$$

\section{Determination of drug entrapment efficiency}

Ten milligram of accurately weighed microspheres was crushed in a glass mortar-pestle and was then suspended in $10 \mathrm{ml}$ of $\mathrm{pH} 6.8$ phosphate buffer solution. After $24 \mathrm{~h}$ the solution was filtered and the filtrate was assessed for drug content. The drug entrapment was calculated using the formula (Patel and Patel 2007):

$$
\text { Entrapment efficiency }(\%)=\frac{\text { Calculated drug concentration }}{\text { Theoretical drug concentration }} \times 100
$$

\section{Micromeritics study}

Carr's compressibility index and Hausner ratio were determined. Bulk density and tapped density were measured by a volumetric cylinder. Particles having excellent flow properties will have value of Carr's compressibility index, Hausner ratio and angle of repose in the range of 5-10, 1.00-1.11 and 25-30 respectively (Lumay et al. 2012).

\section{Surface morphology study with the help of scanning electron microscope (SEM) analysis}

The shape and surface morphology of the microspheres was visualized by scanning electron microscopy (s-3400 N, Hitachi). The samples were prepared by lightly sprinkling the microspheres on a double-sided adhesive tape fixed on aluminum stubs. The stubs were then put into an ion sputter coater and coated with platinum in the inert environment of argon. After coating, the samples were arbitrarily examined by an electron beam to get 3D images of the microspheres. The effects of polymer concentration on the microsphere shape, integrity and their drug release pattern were studied.

\section{In vitro dissolution study of Fexofenadine $\mathrm{HCl}$ microspheres}

The in vitro drug release profile from various formulations of microspheres were performed in a paddle type (Type II) dissolutiona pparatus in simulated intestinal fluid (phosphate buffer solution, PBS, pH 6.8) at $100 \mathrm{rpm}$ and temperature was maintained fixed at $37{ }^{\circ} \mathrm{C}$. The dissolution process was carried out for $10 \mathrm{~h}$ and $10 \mathrm{ml}$ dissolution sample from each dissolution media was withdrawn at a predetermined intervals of 
$30 \mathrm{~min}, 1 \mathrm{st}, 2 \mathrm{nd}, 3 \mathrm{rd}, 4 \mathrm{th}, 5 \mathrm{th}, 6 \mathrm{th}, 7 \mathrm{th}, 8 \mathrm{th}$, 9th and 10th $\mathrm{h}$ and the release was measured by UV spectrophotometric method at $259 \mathrm{~nm}$ (Manekar et al. 1992).

\section{Data analysis}

To analyze the in vitro release data various kinetic models were used to describe the release kinetics. The zero order rate equation (1) describes the systems where the drug release rate is independent of its concentration. The first order equation (2) describes the release from system where release rate is concentration dependent. Higuchi (1963) described the release of drugs from microspheres as a square root of time dependent process based on Fickian diffusion equation (3). The Hixson-Crowell cube root law equation (4) describes the release from systems where there is a change in surface area and diameter of particles or tablets.

$$
\mathrm{C}=\mathrm{k}_{0} \mathrm{t}
$$

where $K_{0}$ is zero-order rate constant expressed in units of concentration/time and $t$ is the time.

$$
\log C_{0}-\log C=k t / 2.303
$$

where $\mathrm{C}_{0}$ is the initial concentration of drug and $\mathrm{K}$ is first order constant.

$$
\mathrm{Q}=\mathrm{Kt}_{1 / 2}
$$

where $\mathrm{K}$ is the constant reflecting the design variables of the system.

$$
\mathrm{Q}_{0}^{1 / 3}-\mathrm{Q}_{\mathrm{t}}^{1 / 3}=\mathrm{K}_{\mathrm{HC}} \mathrm{t}
$$

where $Q_{t}$ is the amount of drug released in time $t, Q_{0}$ is the initial amount of the drug in tablet and $\mathrm{K}_{\mathrm{HC}}$ is the rate constant for Hixson-Crowell rate equation.

\section{Successive fractional dissolution time}

To characterize the drug release rate in different experimental conditions, time to release $25 \%$ drug $\left(\mathrm{T}_{25 \%}\right)$, time to release $50 \%$ drug $\left(\mathrm{T}_{50 \%}\right)$, time to release $50 \%$ drug $\left(\mathrm{T}_{80 \%}\right)$ and mean dissolution time (MDT) were calculated from dissolution data.

\section{Statistical analysis}

Statistical analysis of the results was performed by using one-way analysis of variance (ANOVA) followed by Dennett's $t$ test for comparisons. The limit of significance was set at $\mathrm{P}<0.05$.

\section{Compatibility studies of drug and polymer within Fexofenadine $\mathrm{HCl}$ microspheres Fourier transform infrared spectrophotometry (FTIR)}

The IR spectrum of the pure drug, pure polymer, physical mixture of drug and polymer and optimized microsphere formulations were obtained to evaluate the chemical integrity and compatibility of the drug with the polymers in the microspheres. 


\section{Differential scanning calorimetery (DSC)}

DSC study was carried out to evaluate the interaction between the drug and the polymers in the microspheres by using a differential scanning calorimeter (DSC 60, Shimadzu).

\section{Results and discussion}

\section{Production yield (\%) of microspheres}

Figure 1 shows that yield did not follow any particular pattern of change with drug loading.

The practical production yield was found to be the highest for formulation $\mathrm{F} 4$ containing high viscosity HPMC K100 M CR (40 \% drug loading). For microspheres prepared with HPMC K100 M CR, the lowest value was found to be $80.45 \%$ for F1 (66.66 \% drug loading).

\section{Drug entrapment efficiency (\%) of microspheres}

The entrapment efficiency was determined spectrophotometrically by measuring the absorbance at $259 \mathrm{~nm}$ using $\mathrm{pH} 6.8$ phosphate buffer solution. As Fig. 1 suggests, entrapment efficiency was found to be minimum for formulation F1 (78.86 \%) and maximum for formulation F5 $90.94 \%$. It was improved with an increase in polymer concentration because a higher amount of polymer was available for cross linking which prevented drug diffusion from the microspheres (Panchaxari et al. 2013).

\section{Micromeritics study of microspheres prepared with HPMC K100 M CR}

The microspheres exhibited good to excellent flow properties (Table 2). The true density and bulk density values were in the range of $0.31-0.47$ and $0.27-0.43 \mathrm{~g} / \mathrm{cm}^{3}$ respectively. The most acceptable flow ability was showed by F3 (50\% drug loading) and the worst flow properties were exhibited by F1 (66.66 \% drug loading). Using these values Carr's

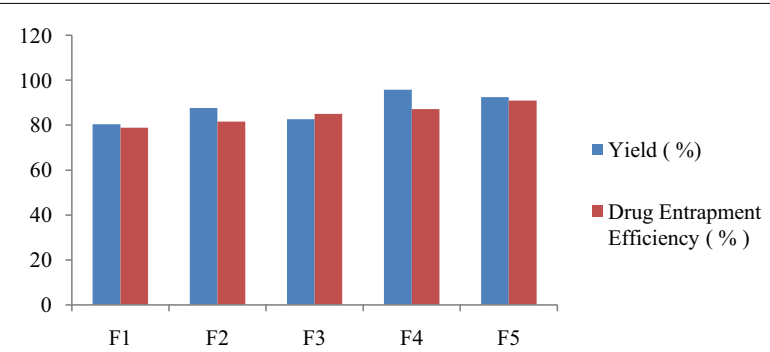

Fig. 1 Production yield (\%) and drug entrapment efficiency of microspheres

Table 2 Results of micromeritics study of microspheres

\begin{tabular}{lllll}
\hline Formulation & Bulk density $(\mathbf{g} / \mathbf{m l})$ & Tapped density $\mathbf{( g / m l )}$ & Carr's compressibility index & Hausner ratio \\
\hline F1 & 0.27 & 0.31 & 12.90 & 1.15 \\
F2 & 0.39 & 0.43 & 9.30 & 1.10 \\
F3 & 0.44 & 0.46 & 4.35 & 1.05 \\
F4 & 0.34 & 0.37 & 8.11 & 1.09 \\
F5 & 0.43 & 0.47 & 8.51 & 1.09 \\
\hline
\end{tabular}


index and Hausner ratio were found to be in the range of 8.51-12.90 and 1.09-1.15 respectively. The result inferred that the prepared microspheres possess good to excellent flow properties.

\section{Observation of particle morphology by scanning electron microscope (SEM)}

Figure 2 shows that, maximum microspheres were found to be almost spherically shaped when observed with an optical microscope, but when observed by SEM they were found to be slightly irregular shape and rough surface which is responsible for the sustained, but earlier drug release. The surface morphology of the microspheres (F1-F4) was dependent on the concentration of polymers. Microspheres having a higher proportion of polymers were found to have a smooth surface due to the availability of more polymers for crosslinking causing the entrapment of more drug. Batch F1 (66.67 \% drug loading), represented by Fig. $2 \mathrm{a}$, is the microsphere with a rough and fractured surface. The shape of the microspheres of Batch F5 (33.33 \% drug loading), represented by Fig. 2b, is almost spherical and the surface of the particles is smoother. There was no significant level of fusion among particles. Presence of pores or cracks may help releasing the drug since these facilitate the penetration of dissolution medium into the microsphere. Roughness of the surface increases the chances of wetting and contact of water with the microsphere than the smoother one nature of the surface influences the constancy, quality, integrity and dissolution characteristics of the microspheres. At high concentration, some of the microspheres were fused to each other, which may be due to the presence of higher amount of water, which slowly evaporates upon stirring, causing the particles to come in contact with each other.

In vitro dissolution and kinetic studies of Fexofenadine $\mathrm{HCl}$ loaded polymeric microsphere HPMC K 100 M CR polymer was used as the release retardant polymer to prepare Fexofenadine $\mathrm{HCl}$ loaded microspheres having drug loading 33.33, 40, 50, 60, $66.66 \%$ with the formulation F1, F2, F3, F4 and F5 respectively. After preparation according to formulation shown in the (Table 1), their dissolution studies were carried out in paddle method (USP apparatus II) in simulated intestinal fluid (pH 6.8) at $100 \mathrm{rpm}$ at $37^{\circ} \mathrm{C}$. The release profile of the formulations was monitored up to $10 \mathrm{~h}$. The rate of drug release was found to be inversely related to the amount of HPMC K 100 M CR present in the

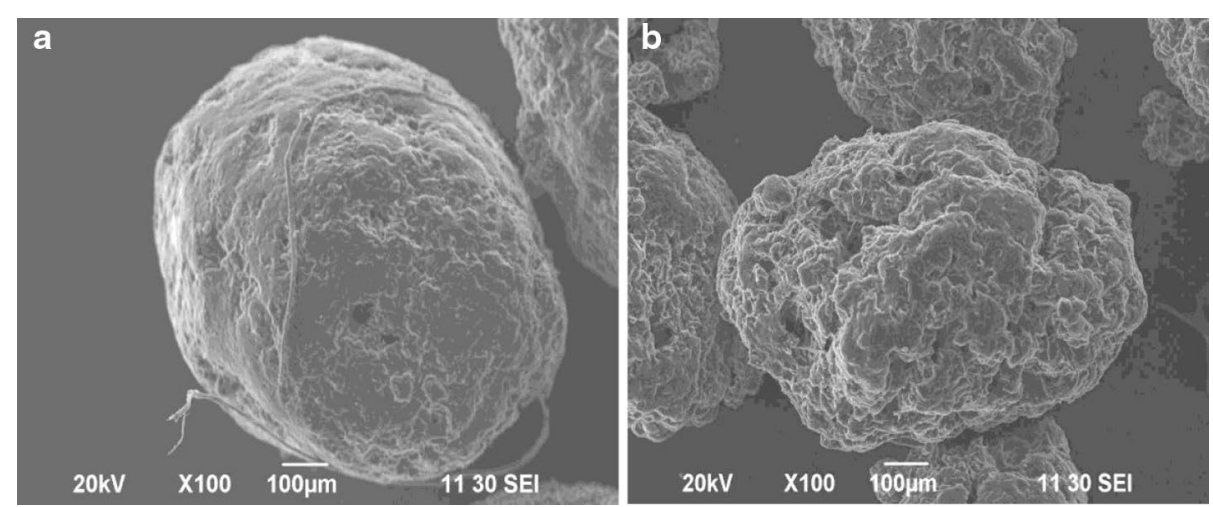

Fig. 2 Scanning electron microscopic view of microspheres. a Formulation F1 (66.67 \% drug loading) and b formulation F5 (33.33 \% drug loading) 
formulations, i.e. the rate of drug release increased with decrease in the polymer content. Figure 3 shows in vitro release kinetics of five formulations (F1-F5) of Fexofenadine $\mathrm{HCl}$ microspheres prepared with HPMC K100 M CR: A representing zero order release pattern, B showing first order release profile, $C$ giving the Higuchi impact, D characterizing Korsmeyer-Peppas plot and E signifying Hixson-Crowell plot. Among all the batches, F1-F5 (Table 1), F5 showed best release retardant property. From Table 3, it can be inferred that the percent release of drug after $10 \mathrm{~h}$ was $85.31 \%$ from F5, showing the highest release retarding property. Best fitted model for this formulation were Higuchi $\left(R^{2}=0.990\right)$, Korsmeyer-Peppas $\left(R^{2}=0.985\right)$ and Hixson-Crowell $\left(R^{2}=0.978\right)$. F1 showed least release retardant property. After dissolution of microsphere the percent release of drug after $10 \mathrm{~h}$ was $85.31 \%$ from F1. First order $\left(\mathrm{R}^{2}=0.983\right)$, Higuchi $\left(R^{2}=0.991\right)$, Korsmeyer-Peppas $\left(R^{2}=0.975\right)$ and Hixson-Crowell $\left(R^{2}=0.981\right)$ models

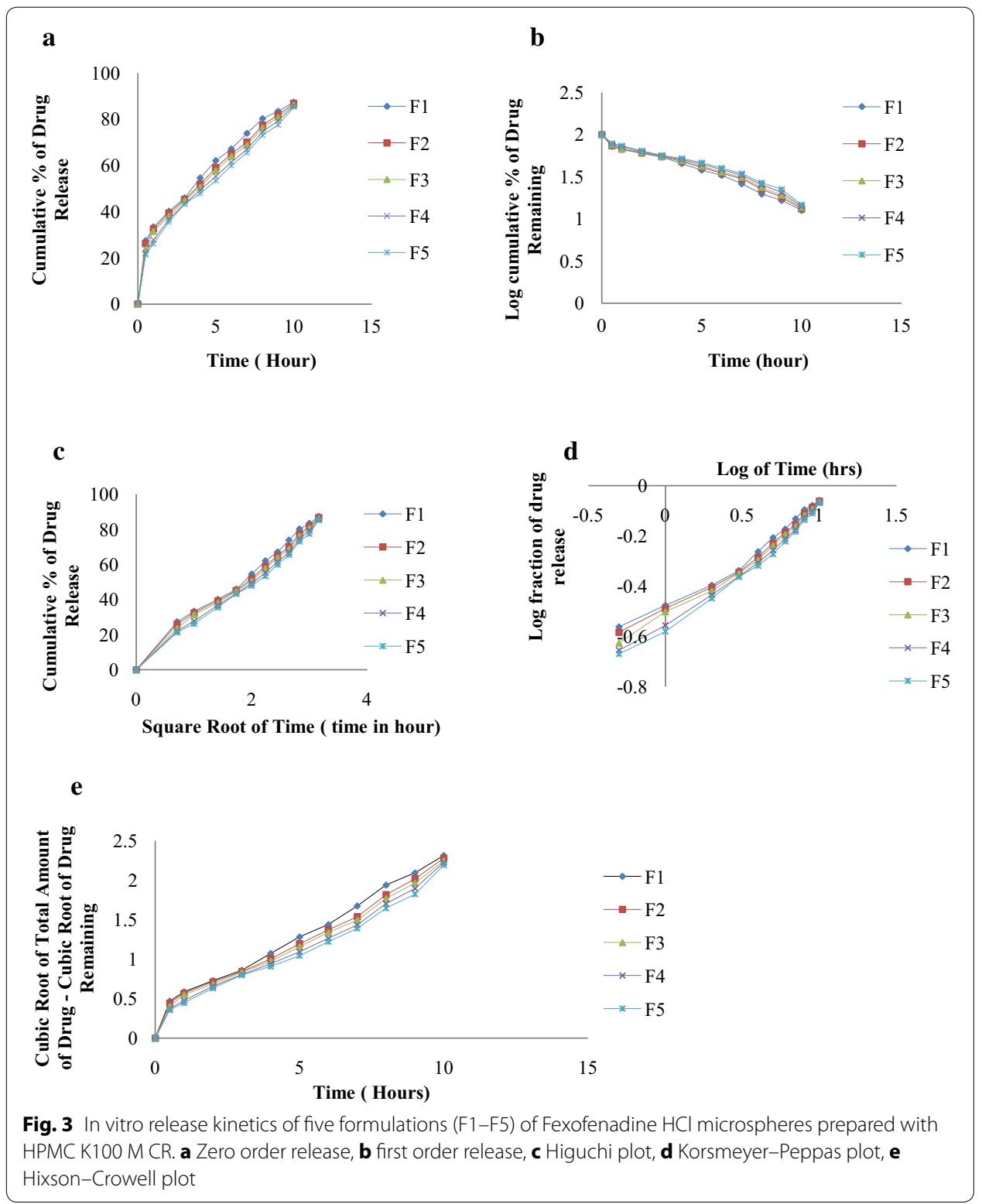


Table 3 Release rate constants and $R^{2}$ values for different release kinetics of five formulations (F1, F2, F3, F4 and F5) of Fexofenadine $\mathrm{HCl}$ microspheres

\begin{tabular}{|c|c|c|c|c|c|c|c|c|c|c|c|}
\hline \multirow[t]{2}{*}{ Formulation } & \multicolumn{2}{|c|}{ Zero order } & \multicolumn{2}{|c|}{ First order } & \multicolumn{2}{|c|}{ Higuchi } & \multicolumn{3}{|c|}{ Korsmeyer-Peppas } & \multicolumn{2}{|c|}{$\begin{array}{l}\text { Hixson- } \\
\text { Crowell }\end{array}$} \\
\hline & $\mathrm{K}_{0}$ & $\mathrm{R}^{2}$ & $\mathrm{~K}_{1}$ & $\mathrm{R}^{2}$ & $\mathrm{~K}_{\mathrm{H}}$ & $\mathrm{R}^{2}$ & $\mathrm{n}$ & $\mathrm{K}_{\mathrm{KP}}$ & $\mathrm{R}^{2}$ & $\mathrm{~K}_{\mathrm{HC}}$ & $\mathrm{R}^{2}$ \\
\hline F1 & 7.378 & 0.920 & -0.187 & 0.983 & 26.48 & 0.991 & 0.403 & 0.33 & 0.975 & 0.206 & 0.981 \\
\hline F2 & 7.236 & 0.927 & -0.177 & 0.974 & 25.86 & 0.989 & 0.406 & 0.32 & 0.976 & 0.197 & 0.979 \\
\hline F3 & 7.247 & 0.934 & -0.173 & 0.973 & 25.84 & 0.992 & 0.428 & 0.30 & 0.983 & 0.194 & 0.980 \\
\hline F4 & 7.272 & 0.946 & -0.168 & 0.968 & 25.77 & 0.991 & 0.453 & 0.28 & 0.986 & 0.191 & 0.980 \\
\hline F5 & 7.204 & 0.948 & -0.161 & 0.964 & 25.46 & 0.990 & 0.462 & 0.27 & 0.985 & 0.187 & 0.978 \\
\hline
\end{tabular}

fit best to F1. F1-F3 followed Fickian transport and F4-F5 followed non-Fickian transport (Table 4).

\section{Successive fractional dissolution time}

Successive fractional dissolution time was observed to be highest for F5 and lowest for F1 (Fig. 4).

\section{Analysis of impact of \% drug loading on different formulation}

Table 5 reveals that, decrease in drug loading has no significant effect on \% yield but has significant increasing effect on \% drug entrapment efficiency. The time required for $50 \%$ of drug release $\left(\mathrm{T}_{50 \%}\right)$ increases with increase in the total amount of HPMC K100 M CR (decrease in drug loading). Statistically it shows that, with increase in the total amount

Table 4 The best fitted model and mechanism of drug release from F1, F2, F3, F4 and F5

\begin{tabular}{llll}
\hline Formulation & Best fitted model & n value & Release mechanism \\
\hline F1 & $\begin{array}{l}\text { First order, Higuchi, Korsmeyer-Peppas } \\
\text { and Hixson-Crowell }\end{array}$ & 0.403 & Fickian transport \\
F2 & $\begin{array}{l}\text { First order, Higuchi, Korsmeyer-Peppas } \\
\text { and Hixson-Crowell }\end{array}$ & 0.406 & Fickian transport \\
F3 & $\begin{array}{l}\text { First order, Higuchi, Korsmeyer-Peppas } \\
\text { and Hixson-Crowell }\end{array}$ & 0.428 & Fickian transport \\
F4 & $\begin{array}{l}\text { Higuchi, Korsmeyer-Peppas and Hixson-Crowell } \\
\text { F5 }\end{array}$ & 0.453 & Non-Fickian/anomalous transport \\
\hline
\end{tabular}

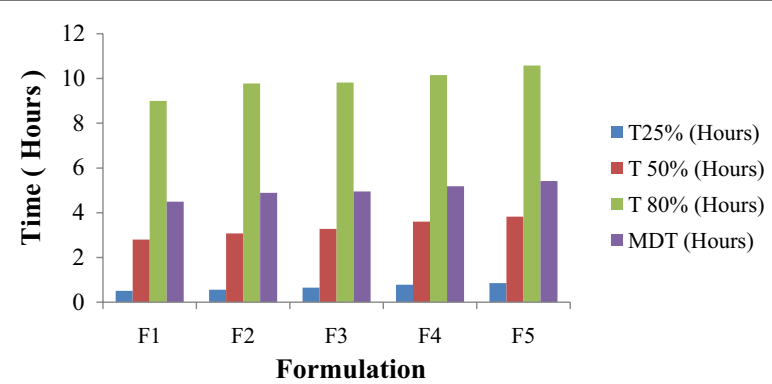

Fig. 4 Bar diagram representing successive fractional dissolution time of five formulations $F 1, F 2, F 3, F 4$ and F5 
Table 5 Summary of impact analysis of \% drug loading on different formulation parameters of formulations F1-F5 using simple linear regression model (level of significance 0.05)

\begin{tabular}{|c|c|c|c|c|}
\hline Formulation parameters & $\begin{array}{l}\text { Regression coef- } \\
\text { ficient }(\beta)\end{array}$ & $P$ value & Result & Comment \\
\hline Yield (\%) & 0.04153 & 0.10648 & $P$ value $>0.05$ & Statistically insignificant \\
\hline $\begin{array}{l}\text { Drug entrapment } \\
\text { efficiency (\%) }\end{array}$ & 0.037828 & 0.000848 & $P$ value $<0.05$ & Statistically significant \\
\hline $\begin{array}{l}\text { Time required for } 50 \% \\
\text { of drug release }\left(\mathrm{T}_{50 \%}\right)\end{array}$ & 0.0032752 & 0.000314 & P value $<0.05$ & Statistically significant \\
\hline
\end{tabular}

of HPMC K100 M CR by $1 \mathrm{mg}, \mathrm{T}_{50 \%}$ increases by $0.0032752 \mathrm{~h}$. Considering the level of significance 0.05 , P value has been found to be 0.000314 for formulations F1-F5. This indicates that, $\mathrm{P}$ value is $<0.05$. So it can be concluded that, the effect of the change in the amount of HPMC K $100 \mathrm{M} \mathrm{CR}$ on $\mathrm{T}_{50 \%}$ is statistically significant (Fig. 5).

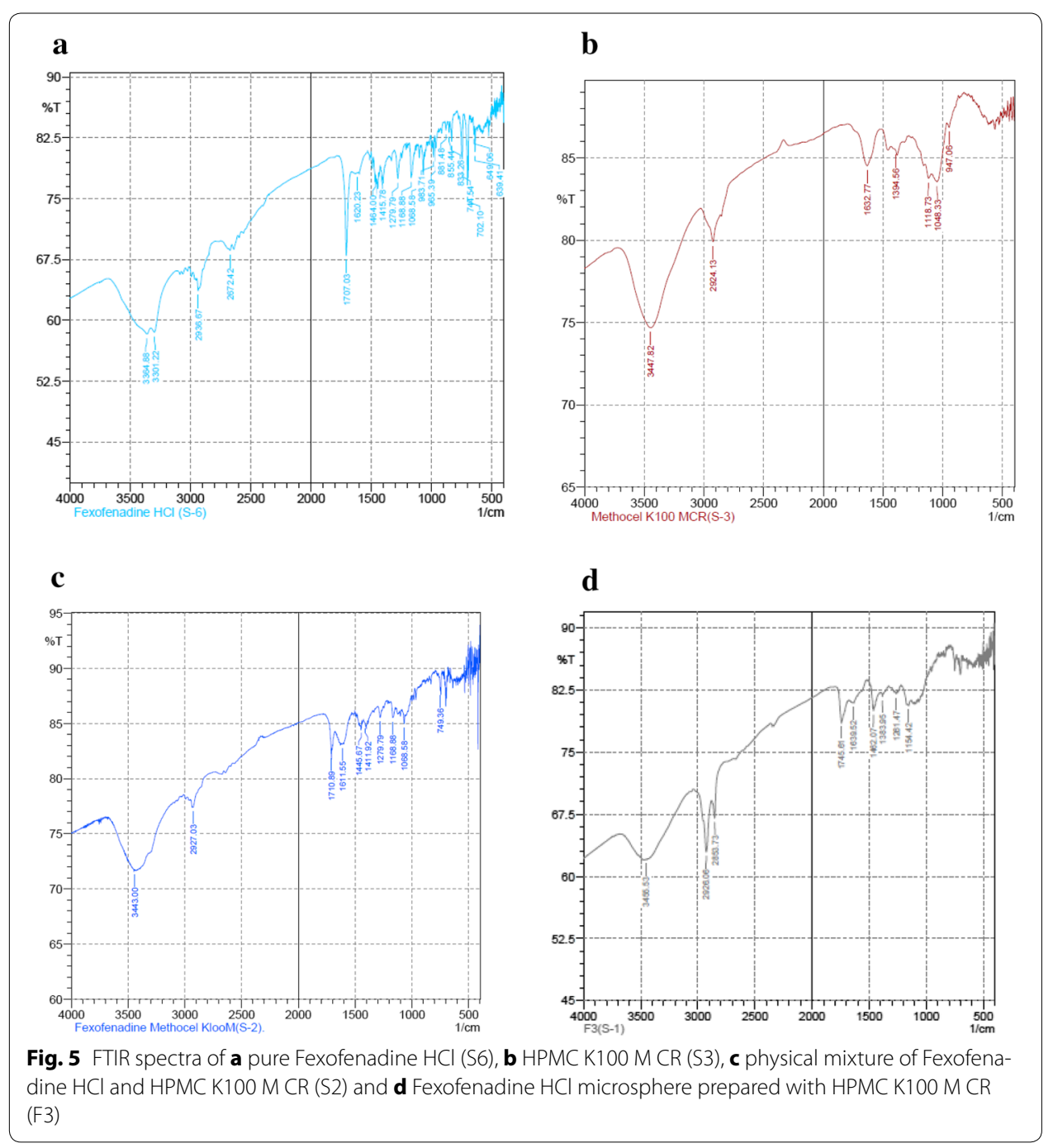




\section{Fourier transform infrared spectroscopy (FTIR)}

FTIR spectra of pure Fexofenadine $\mathrm{HCl}$ (S6), physical mixture of Fexofenadine $\mathrm{HCl}$ and HPMC K100 M CR (S2) and Fexofenadine HCl microspheres prepared with HPMC K100 M CR (F3) were observed and shown in Fig. 5. The FTIR spectra of pure Fexofenadine $\mathrm{HCl}$ depict characteristic absorption band at 3364.88, 1707.03, 1464, 1279.79 and $1168.88 \mathrm{~cm}^{-1}$ which represent the presence of broad, $\mathrm{O}-\mathrm{H}$ stretching vibrations, carbonyl $(\mathrm{C}=\mathrm{O})$ stretching of Carboxylic acid, aromatic $\mathrm{C}=\mathrm{C}$ stretching and $\mathrm{C}-\mathrm{O}$ stretching vibration of tertiary alcohol respectively. According to Fig. 5, the FTIR spectra of Fexofenadine $\mathrm{HCl}$ loaded microsphere (F3) show characteristic absorption band at 3364.88, 1707.03, 1464, 1279.79, and $1168.88 \mathrm{~cm}^{-1}$ which represent the presence of broad, $\mathrm{O}-\mathrm{H}$ stretching vibrations, carbonyl $(\mathrm{C}=\mathrm{O})$ stretching of carboxylic acid, aromatic $\mathrm{C}=\mathrm{C}$ stretching and $\mathrm{C}-\mathrm{O}$ stretching vibration of tertiary alcohol respectively (Table 4). It indicates no change of functional groups (Fig. 6).

\section{Differential scanning calorimetric (DSC) study}

DSC studies were conducted for pure Fexofenadine HCl, HPMC K100 M CR and their physical mixtures and F3 (microspheres of drug prepared with HPMC K100 M CR). The data obtained from all of these samples are viewed in Fig. 6 as combined thermogram of drug, polymer and microspheres prepared with HPMC K100 M CR. No drastic change occurred to the melting point of the microspheres in comparison with pure Fexofenadine $\mathrm{HCl}$. So it can be said there is no such incompatibilities in the physical mixture or in the microspheres prepared with HPMC K100 M CR in comparison to pure Fexofenadine $\mathrm{HCl}$.

\section{Conclusion}

Polymeric microspheres of Fexofenadine $\mathrm{HCl}$ were prepared successfully by emulsification-solvent evaporation technique using K100 M CR. In this study, it has been demonstrated that HPMC K100 M CR microspheres containing Fexofenadine $\mathrm{HCl}$ can be an excellent candidates for consideration in drug delivery system with a sustained effect. As the results suggest, F5 can be considered as the best formulation.

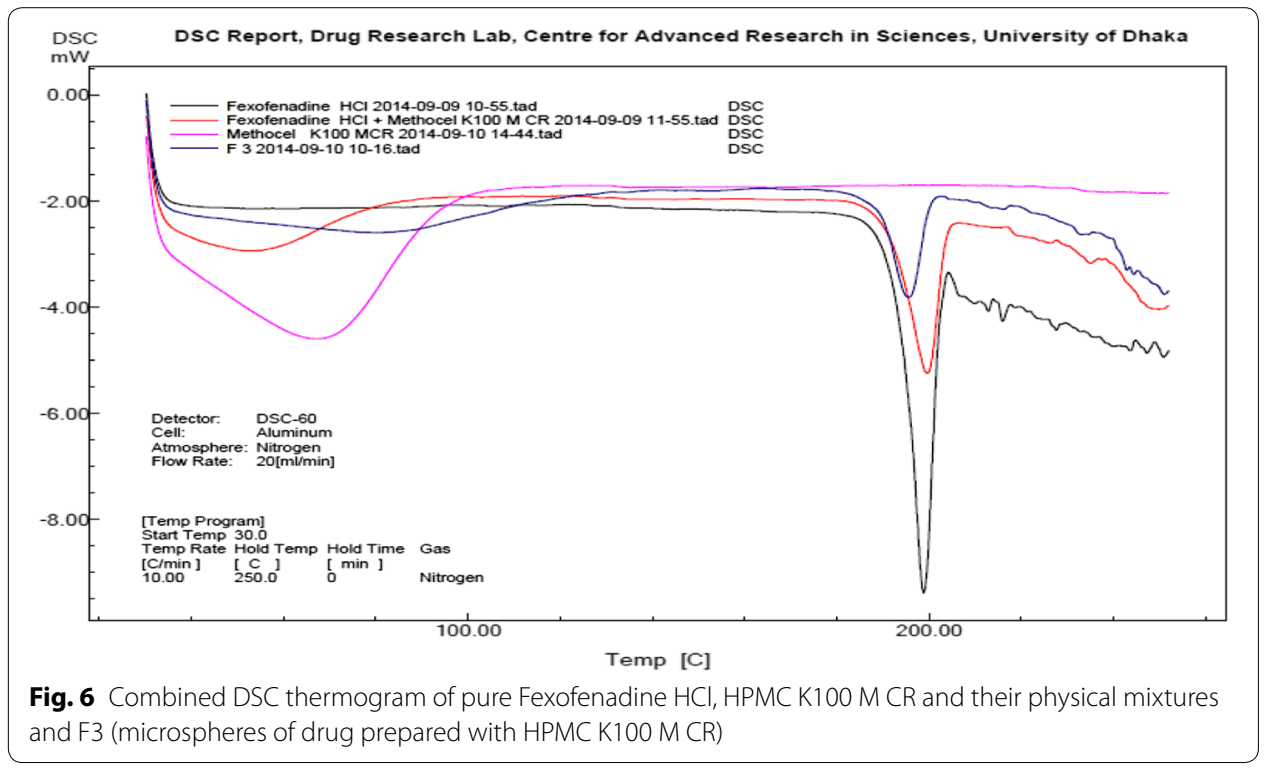




\section{Authors' contributions}

PA performed the laboratory work, collected all data, performed the statistical analyses and drafted the manuscript. IH and MSR made substantial contribution in designing the study and interpretation of data. All authors read and approved the final manuscript.

\section{Acknowledgements}

The authors are grateful to Department of Pharmacy, University of Dhaka and for the laboratory facilities, support and encouragement to carry out this research work. We are thankful to Incepta Pharmaceuticals Ltd. for providing Fexofenadine $\mathrm{HCl}$, the drug as a generous gift for the study.

Competing interests

The authors declare that they have no competing interests.

Received: 12 September 2015 Accepted: 10 May 2016

Published online: 25 May 2016

\section{References}

Ayon NJ, Hasan I, Islam MS, Reza MS (2014) Preparation and characterization of gliclazide incorporated cellulosic microspheres: studies on drug release. Compatibility and micromeritics. Dhaka Univ J Pharm Sci 13(2):149-166

Bolourtchian N, Karimi K, Aboofazeli R (2005) Preparation and characterization of ibuprofen microspheres. J Microencapsul 22(5):529-538

El-Kamel A, Al-Shora DH, El-Sayed YM (2006) Formulation and pharmacodynamic evaluation of captopril sustained release microcapsules. J Microencapsul 23(4):389-404

Higuchi T (1963) Mechanism of sustained-action medication. Theoretical analysis of rate of release of solid drugs dispersed in solid matrices. J Pharm Sci 52:1145-1149

Jalil R, Nixon JR (1989) Microencapsulation using poly (L-lactic acid) I: microcapsule properties affected by the preparative technique. J Microencapsul 6:473-484

Lumay G, Boschini F, Traina K, Bontemp S, Remy JC, Cloots R, Vandewalle N (2012) Measuring the flowing n-properties of powders and grains. Powder Technol 224:19-27

Manekar NC, Puranik PK, Joshi SB (1992) Microencapsulation of propranolol hydrochloride by the solvent evaporation technique. J Microencapsul 9(1):63-66

Panchaxari MD, Amit MB, Vinayak SM, Anand PG, Vivek WS, Prashant SS (2013) An improvement of the efficacy of moxifloxacin $\mathrm{HCl}$ for the treatment of bacterial keratitis by the formulation of ocular mucoadhesive microspheres. Sci Pharm 81:259-280

Parida KR, Panda SK, Ravanan P, Roy H, Manickam M, Talwar P (2008) Microparticles based drug delivery systems: preparation and application in cancer therapeutics. Int Arch Appl Sci Technol 4(3):68-75

Patel JK, Patel MM (2007) Stomach specific anti-helicobacter pylori therapy: preparation and evaluation of amoxicillinloaded chitosan mucoadhesive microspheres. Curr Drug Deliv 4:41-50

Product Information: Allegra, Fexofenadine. Hoechst Marion Roussel, Kansas City (PI revised 6/98) reviewed 1/2000

Product Information: Allegra ${ }^{\circledR}$, Fexofenadine. Aventis Pharmaceuticals, Kansas City (PI revised 11/2000) reviewed 10/2001

Raut NS, Somvanshi S, Jumde AB, Khandelwal HM, Umekar MJ, Kotagale NR (2013) Ethyl cellulose and hydroxypropyl methyl cellulose buoyant microspheres of metoprolol succinate: influence of pH modifiers. Int J Pharm Investig 3(3):163-170

Raval JP, Naik DR, Patel PS (2011) Preparation and evaluation of cellulose acetate butyrate microspheres containing diclofenac sodium. Int J Drug Formul Res 2(4):247-259

Uddin MR, Rashid MM, Alam MR (2013) In vitro evaluation of oral extended release drug delivery system for trimetazidine dihydrochloride using methocel polymers. Int J Pharm Pharm Sci 5(4):329-339

\section{Submit your manuscript to a SpringerOpen ${ }^{\circ}$ journal and benefit from:}

- Convenient online submission

- Rigorous peer review

- Immediate publication on acceptance

- Open access: articles freely available online

- High visibility within the field

- Retaining the copyright to your article

Submit your next manuscript at springeropen.com 